Xindi Xu, Xun Ma, Meifen Huang, Tianyu Li and Qiong Wu*

\title{
Crystal structure of 4-bromo- $N^{\prime}$-[(3-bromo- 2-hydroxyphenyl)methylidene]benzohydrazide methanol solvate, $\mathrm{C}_{15} \mathrm{H}_{14} \mathrm{Br}_{2} \mathrm{~N}_{2} \mathrm{O}_{3}$
}

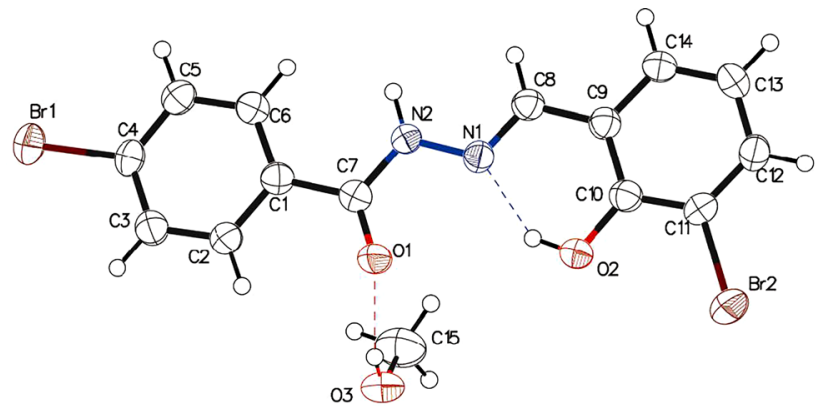

https://doi.org/10.1515/ncrs-2020-0540

Received October 18, 2020; accepted November 12, 2020;

published online December 4, 2020

\section{Abstract}

$\mathrm{C}_{15} \mathrm{H}_{14} \mathrm{Br}_{2} \mathrm{~N}_{2} \mathrm{O}_{3}$, triclinic, $P \overline{1}$ (no. 2), $a=7.2748(3) \AA$, $b=9.0786(4) \AA, c=12.8613(5) \AA, \alpha=99.458(2)^{\circ}$, $\beta=100.401(2)^{\circ}, y=99.499(2)^{\circ}, V=807.35(6) \AA^{3}, Z=2$, $R_{g t}(F)=0.0253, w R_{\text {ref }}\left(F^{2}\right)=0.0673, \mathrm{~T}=150.0 \mathrm{~K}$.

CCDC no.: 2039205

The molecular structure is shown in the Figure. Table 1 contains crystallographic data and Table 2 contains the list of the atoms including atomic coordinates and displacement parameters.

\section{Source of material}

3-Chloro-2-hydroxybenzaldehyde (0.156 g, $1.0 \mathrm{mmol})$ and 4-bromobenzohydrazide ( $0.215 \mathrm{~g}, 1 \mathrm{mmol})$ were added to a stirring $30 \mathrm{~mL}$ methanol solution and refluxed for $12 \mathrm{~h}$. The mixture was filtered and and kept undisturbed at room temperature. The colorless square crystals of title compound were afforded after one week.

\footnotetext{
*Corresponding author: Qiong Wu, Department of Chemical Science and Technology, Kunming University, Kunming, Yunnan 65200, P. R. China, E-mail: wuqiongkm@163.com. https://orcid.org/0000-00017931-6750

Xindi Xu, Xun Ma, Meifen Huang and Tianyu Li, Department of Chemical Science and Technology, Kunming University, Kunming, Yunnan 65200, P. R. China
}

Table 1: Data collection and handling.

\begin{tabular}{|c|c|}
\hline Crystal: & Colourless block \\
\hline Size: & $0.12 \times 0.12 \times 0.16 \mathrm{~mm}$ \\
\hline Wavelength: & Mo $K \alpha$ radiation $(0.71073 \AA$ ̊ $)$ \\
\hline$\mu$ : & $6.0 \mathrm{~mm}^{-1}$ \\
\hline Diffractometer, scan mode: & Bruker APEX-II, $\varphi$ and $\omega$ \\
\hline$\theta_{\max }$, completeness: & $26.4^{\circ},>99 \%$ \\
\hline$N(h k l)_{\text {measured }}, N(h k l)_{\text {unique }}, R_{\text {int }}:$ & $15,976,3303,0.036$ \\
\hline Criterion for $I_{\mathrm{obs}}, N(h k)_{\mathrm{gt}}$ : & $I_{\text {obs }}>2 \sigma\left(I_{\text {obs }}\right), 2746$ \\
\hline$N(\text { param })_{\text {refined }}:$ & 202 \\
\hline Programs: & Bruker [1], Olex2 [2], SHELX [3, 4] \\
\hline
\end{tabular}

\section{Experimental details}

The structure was solved and refined with the Olex2 program [2] as an interface together with the SHELXT and SHELXL programs $[3,4]$. All $\mathrm{H}$ atoms were placed in geometrically idealized positions and refined using a riding model, with $\mathrm{C}-\mathrm{H}=0.98$ (methyl), $\mathrm{O}-\mathrm{H}=0.84$ (phenolic hydroxyl), $0.95 \AA$ (aryl), and with $U_{\text {iso }}(\mathrm{H})=1.2$ $U_{\text {eq }}(\mathrm{C})$ for $\mathrm{H}$ atoms on methyl, phenolic hydroxyl and aryl.

\section{Comment}

The design and synthesis of supramolecular networks of coordination polymers has been one of the academic frontiers in recent years [5, 6]. As a part of our current research interest in exploring the relationship between molecular structure and physicochemical properties of halogenated Schiff-base compounds [7, 8], in this work, we report a new hydrazone.

$\mathrm{X}$-ray diffraction analysis reveals that the asymmetric unit of the structure contains a planar hydrazone molecule and a methanol molecule, as shown in the figure. The five non-hydrogen conjugated atoms $[\mathrm{C}(=\mathrm{O}) \mathrm{N}-\mathrm{N}=\mathrm{C}]$ constitute the central chromophore and over all exhibit the $E$ configuration. The dihedral angles formed between the central plane and the least-squares planes through the flanking hydroxy- and bromo-phenyl rings are $3.49(6)^{\circ}$ and $1.95(7)^{\circ}$, respectively. The co-planar geometry between the central chromophore and hydroxyphenyl ring generates an intra-

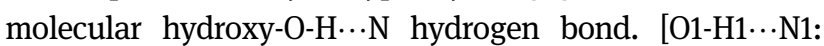


Table 2: Fractional atomic coordinates and isotropic or equivalent isotropic displacement parameters $\left(\AA^{2}\right)$.

\begin{tabular}{|c|c|c|c|c|}
\hline Atom & $x$ & $y$ & $z$ & $U_{\text {iso }}{ }^{\star} / U_{\text {eq }}$ \\
\hline $\mathrm{Br} 1$ & $0.10184(4)$ & $0.49086(3)$ & $0.77333(2)$ & $0.04662(10)$ \\
\hline $\mathrm{Br} 2$ & $0.34294(4)$ & 1.34147 (3) & $0.03626(2)$ & $0.05154(10)$ \\
\hline C1 & $0.1306(3)$ & $0.7890(3)$ & 0.51219 (19) & $0.0344(5)$ \\
\hline $\mathrm{C} 2$ & $0.2973(4)$ & $0.7758(3)$ & $0.5805(2)$ & $0.0381(5)$ \\
\hline $\mathrm{H} 2 \mathrm{~B}$ & 0.4176 & 0.8273 & 0.5733 & $0.046^{\star}$ \\
\hline C3AA & $0.4688(5)$ & $0.6853(4)$ & 0.2888 (3) & $0.0709(10)$ \\
\hline H3AA & 0.5272 & 0.6428 & 0.2307 & $0.106^{*}$ \\
\hline $\mathrm{H} 3 \mathrm{AB}$ & 0.3538 & 0.7194 & 0.2576 & $0.106^{*}$ \\
\hline $\mathrm{H} 3 \mathrm{AC}$ & 0.4345 & 0.6070 & 0.3299 & $0.106^{\star}$ \\
\hline C3 & $0.2883(4)$ & $0.6879(3)$ & $0.6589(2)$ & $0.0397(6)$ \\
\hline H3 & 0.4016 & 0.6791 & 0.7055 & $0.048^{\star}$ \\
\hline C4 & $0.1129(4)$ & $0.6138(3)$ & 0.66817 (19) & $0.0365(5)$ \\
\hline C5 & $-0.0543(4)$ & $0.6275(3)$ & $0.6030(2)$ & $0.0385(5)$ \\
\hline H5 & -0.1742 & 0.5770 & 0.6116 & $0.046^{\star}$ \\
\hline C6 & $-0.0449(4)$ & $0.7156(3)$ & 0.52495 (19) & $0.0354(5)$ \\
\hline H6 & -0.1590 & 0.7259 & 0.4800 & $0.043^{\star}$ \\
\hline $\mathrm{C} 7$ & $0.1553(4)$ & $0.8851(3)$ & 0.42971 (19) & $0.0342(5)$ \\
\hline $\mathrm{C} 8$ & $-0.1239(3)$ & $1.0016(3)$ & 0.22009 (18) & $0.0340(5)$ \\
\hline $\mathrm{H} 8$ & -0.2486 & 0.9570 & 0.2254 & $0.041^{\star}$ \\
\hline C9 & $-0.0972(4)$ & $1.0896(3)$ & 0.13783 (19) & $0.0343(5)$ \\
\hline C10 & $0.0854(3)$ & $1.1611(3)$ & 0.12888 (19) & $0.0355(5)$ \\
\hline C11 & $0.0982(4)$ & $1.2425(3)$ & $0.0477(2)$ & $0.0377(5)$ \\
\hline C12 & $-0.0614(4)$ & $1.2551(3)$ & $-0.0248(2)$ & $0.0434(6)$ \\
\hline $\mathrm{H} 12$ & -0.0481 & 1.3104 & -0.0805 & $0.052^{\star}$ \\
\hline C13 & $-0.2398(4)$ & 1.1867 (3) & $-0.0154(2)$ & $0.0446(6)$ \\
\hline H13 & -0.3503 & 1.1949 & -0.0644 & $0.054^{*}$ \\
\hline C14 & $-0.2570(4)$ & 1.1065 (3) & $0.0655(2)$ & $0.0393(6)$ \\
\hline H14 & -0.3806 & 1.0614 & 0.0723 & $0.047^{\star}$ \\
\hline N1 & $0.0224(3)$ & $0.9845(2)$ & $0.28554(15)$ & 0.0335 (4) \\
\hline N2 & $-0.0056(3)$ & $0.9018(2)$ & $0.36357(15)$ & $0.0332(4)$ \\
\hline $\mathrm{H} 2 \mathrm{~A}$ & -0.1204 & 0.8620 & 0.3705 & $0.040^{\star}$ \\
\hline 01 & $0.3128(3)$ & $0.9463(2)$ & $0.42131(15)$ & $0.0433(4)$ \\
\hline 02 & $0.2476(2)$ & $1.1526(2)$ & 0.19744 (14) & 0.0404 (4) \\
\hline $\mathrm{H} 2$ & 0.2191 & 1.1033 & 0.2441 & $0.061^{\star}$ \\
\hline 03 & $0.5985(3)$ & $0.8092(2)$ & $0.35738(16)$ & $0.0491(5)$ \\
\hline $\mathrm{H} 3 \mathrm{~A}$ & 0.5388 & 0.8665 & 0.3902 & $0.074^{\star}$ \\
\hline
\end{tabular}

$\mathrm{O} 1-\mathrm{H} 1=0.840(19) \AA, \mathrm{H} 1 \cdots \mathrm{N} 1=1.857(2) \AA, \mathrm{O} 1 \cdots \mathrm{N} 1=2.59(3) \AA$ with an angle at $\left.\mathrm{H} 1=144.92(13)^{\circ}\right]$.

As shown in the figure, the oxygen atom (01) at the carbonyl group accepts a hydrogen bond (H3A-O3) from the methanol molecule [03-H3A $\cdots$ O1: 03-H3A = Distance $0.84 \AA$, $\mathrm{H} 3 \mathrm{~A} \cdots \mathrm{O} 1=1.9808(23) \AA ., 01 \cdots \mathrm{O} 3=2.771(3) \AA$ with angle at $\left.\mathrm{H1A}=156.4(2)^{\circ}\right]^{\circ}$. All geometric parameters are as expected [7-9].

Author contribution: All the authors have accepted responsibility for the entire content of this submitted manuscript and approved submission.

Research funding: Fund for Less Developed Regions of the National Natural Science Foundation of China (No. 31760257); Joint Basic Research Program (partial) of Yunnan Local Undergraduate Universities (2017FH001002); The reserve Academic and Technical Leaders of Yunnan Province (2019HB098).

Conflict of interest statement: The authors declare no conflicts of interest regarding this article.

\section{References}

1. BRUKER. SAINT, APEX2 and SADABS; Bruker AXS Inc.: Madison, Wisconsin, USA, 2009.

2. Dolomanov O. V., Bourhis L. J., Gildea R. J., Howard J. A. K., Puschmann H. OLEX2: a complete structure solution, refinement and analysis program. J. Appl. Crystallogr. 2010, 42, 339-341.

3. Sheldrick G. A short history of SHELX. Acta Crystallogr. 2008, A64, 112-122.

4. Sheldrick G. Crystal structure refinement with SHELXL. Acta Crystallogr. 2015, C71, 3-8.

5. Guillerm V., Kim D., Eubank J. F., Luebke R., Liu X., Adil K., Lah M. S., Eddaoudi M. A supermolecular building approach for the design and construction of metal-organic frameworks. Chem. Soc. Rev. 2014, 43, 6141-6172.

6. Zang X.-S., Wu Q., Chen W., Tan H.-Q., Li Y. G., Wang E. The synthesis and characterization of the 3-D framework of supported Kepleratetype polyoxometalate. Inorg. Chem. Commun. 2011, 14, 590-593.

7. Wu Q., Huang M., Li T., Jiao L., Tu Y., Xu X., Ma X., Tian H., Qiao Y. Crystal and electronic structure of poly-halogenated lanthanide Schiff base complex: insights into halogen bond from structural and theoretical analysis. J. Mol. Struct. 2021, 1225, 129054.

8. Wu Q., Xiao J.-C., Zhou C., Sun J.-R., Huang M.-F., Xu X., Li T., Tian H. Crystal structure and supramolecular architecture of inorganic ligand-coordinated Salen-type Schiff base complex: insights into halogen bond from theoretical analysis and 3D energy framework calculations. Crystals 2020, 10, 334.

9. Lee S., Lo K., Tiekink E.T. Crystal structure of 4-chloro- $\mathrm{N}^{\prime}-[(1 E)-(3-$ ethoxy-2-hydroxyphenyl)methylidene]benzohydrazide - a $Z^{\prime}=3$ structure, $\mathrm{C}_{16} \mathrm{H}_{15} \mathrm{ClN}_{2} \mathrm{O}_{3}$, Z. Kristallogr. NCS 2019, 234, 1341-1344. 